\title{
Correction to: Impacts of ocean acidification on hermit crab communities through contrasting responses of Pagurus filholi (de Man, 1887) and Clibanarius virescens (Krauss, 1843)
}

\section{Morihiko Tomatsuri $[$ - Koetsu Kon}

Published online: 28 August 2019

(C) Springer Nature B.V. 2019

Correction to: Aquat Ecol

https://doi.org/10.1007/s10452-019-09709-0

Figure 2 has been published incorrectly in the original publication of the article. The correct version of Fig. 2 is provided in this correction.
Publisher's Note Springer Nature remains neutral with regard to jurisdictional claims in published maps and institutional affiliations.

The original article can be found online at https:// doi.org/10.1007/s10452-019-09709-0.

M. Tomatsuri $(\bowtie) \cdot$ K. Kon $(\square)$

Shimoda Marine Research Center, University of Tsukuba, Shimoda, Shizuoka 415-0025, Japan

e-mail: toma@shimoda.tsukuba.ac.jp

K. Kon

e-mail: kon@shimoda.tsukuba.ac.jp 
Fig. 2 Abundance of Paguroidea (A), species richness of Paguroidea (B), species richness of carried shells (C), numerical abundance of available shells (D) and species richness of available shells (E) in each station ( $n=10$ per each station). Error bars indicate SD. Station abbreviations shown in Fig. 1. a and b on symbols denote subgroups of stations recognized by Wilcoxon rank sum test $(\mathrm{a}>\mathrm{b})$
A

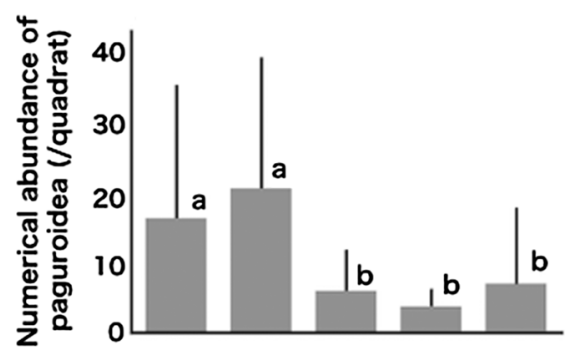

B
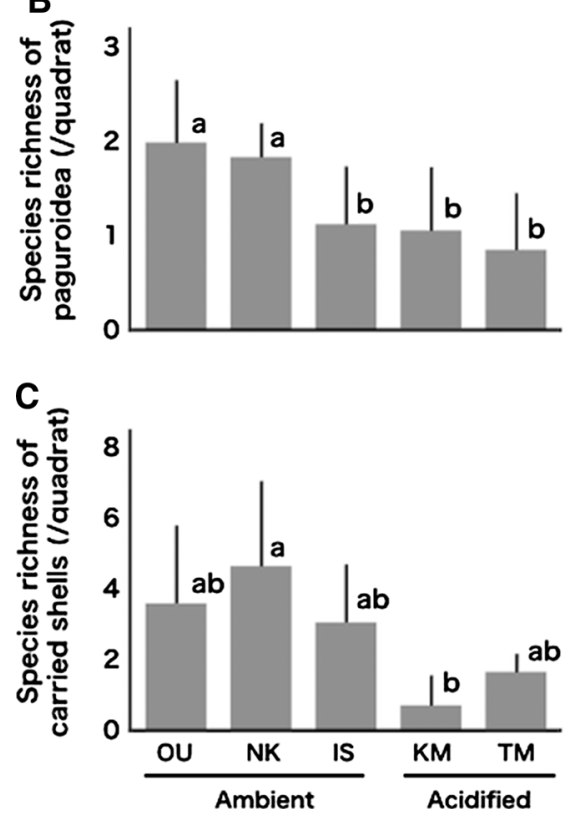

D
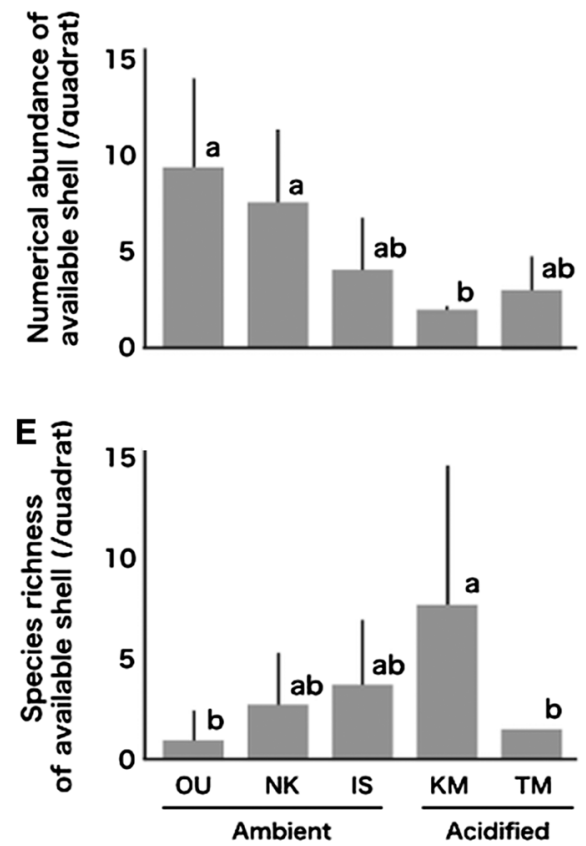